Quim. Nova, Vol. 34, No. 9, 1618-1628, 2011

\title{
SULFETOS VOLATILIZÁVEIS POR ACIDIFICAÇÃO E METAIS EXTRAÍDOS SIMULTANEAMENTE NA AVALIAÇÃO DE SEDIMENTOS DE ÁGUA DOCE
}

\author{
Enelton Fagnani* e José Roberto Guimarães \\ Departamento de Saneamento e Ambiente, Faculdade de Engenharia Civil, Arquitetura e Urbanismo, Universidade Estadual de \\ Campinas, CP 6021, 13083-852 Campinas - SP, Brasil \\ Antonio Aparecido Mozeto e Pedro Sérgio Fadini \\ Departamento de Química, Universidade Federal de São Carlos, CP 676, 13560-970 São Carlos - SP, Brasil
}

Recebido em 1/9/10; aceito em 16/5/11; publicado na web em 29/6/11

\begin{abstract}
ACID VOLATILE SULFIDES AND SIMULTANEOUSLY EXTRACTED METALS IN THE ASSESSMENT OF FRESHWATER SEDIMENTS. This paper discusses the historical and methodological fundaments of the dynamics and quantification of acid volatile sulfides (AVS) and simultaneously extracted metals (SEM) in aquatic sediments. It also discusses the SEM/AVS relationship, which involves several controversial aspects such as sulfide stability, sulfide-organic matter interaction, and the inability to predict the toxicity of organic compounds in the environment. This relationship is an important tool for the inference of metal bioavailability. The use of ecotoxicological tests with target organisms regulated by international standards is also a relevant aspect.
\end{abstract}

Keywords: acid volatile sulfides; simultaneously extracted metals; freshwater sediments.

\section{INTRODUÇÃO}

Com o avanço da ciência e da industrialização, houve uma alteração muito grande no fluxo de elementos químicos entre os principais compartimentos naturais: hidrosfera, atmosfera, litosfera, biosfera e a antroposfera. ${ }^{1}$ A indústria da transformação, a construção civil, a demanda energética, a consequente extração de recursos minerais e a intensificação da produção de alimentos são exemplos de atividades que causam grandes impactos ao ambiente, caracterizando a influência antropogênica no planeta. Os ciclos biogeoquímicos de muitos metais ainda não foram amplamente elucidados, carecendo de pesquisas no sentido de explicar quais as implicações em se perturbar um compartimento ocasionando mobilizações e transporte de espécies químicas antes naturalmente armazenadas de forma estável, com consequentes modificações nos tempos de residência e alterações nos padrões de interações de tais metais com a biosfera.

Neste sentido, estudos de especiação aliados a testes de toxicidade revelam que a quantificação da concentração total de metais existentes em determinado meio não é o melhor indicador de potencial tóxico, já que o fator biodisponibilidade não pode ser estimado por esta variável. Podem ocorrer situações em que um compartimento natural apresente altos teores totais de determinado metal, mas todo ele esteja indisponível para ser incorporado à biota, enquanto que, em outras situações, concentrações mais baixas do mesmo metal são mais deletérias aos seres vivos, dada a sua facilidade de se incorporar aos tecidos, causando intoxicações e podendo levar a sérias injúrias. ${ }^{2-5}$

\section{CARACTERÍSTICAS E IMPORTÂNCIA DOS SEDIMENTOS}

Dentre todos os compartimentos naturais, os sedimentos dos corpos aquáticos se destacam pela sua complexidade e pela capacidade de concentrar e armazenar substâncias potencialmente tóxicas, sendo

*e-mail: enelton@fec.unicamp.br que mesmo após o encerramento das atividades-fonte de determinado processo impactante, e mesmo que a água atenda aos padrões de qualidade, os sedimentos ainda podem se manter contaminados, promovendo processos de bioacumulação por muito tempo. ${ }^{6}$

Segundo a rede mundial de sedimentos, SedNet, o sedimento é uma parte essencial, integral e dinâmica das bacias de rios, estuários e águas costeiras. Muitos sedimentos são derivados do intemperismo e erosão de minerais e solos e contêm também material orgânico. Os sedimentos tendem a ser transportados, sendo que em algumas áreas onde a velocidade do escoamento da água diminui, ocorre a formação de depósitos. Esta sedimentação também ocorre nas áreas alagáveis, nos reservatórios e nos lagos. No caso da foz de rios, há ainda o depósito de material em regiões estuarinas e no leito oceânico. Apresentam ainda um valor ecológico, pois abrigam diferentes formas de vida, suprindo-as com nutrientes e fazendo o mesmo, indiretamente, com toda a cadeia alimentar. ${ }^{7}$

Os sedimentos podem ser formados por carbonatos, hidróxidos, silicatos, sulfetos, fosfatos e material orgânico, em diferentes estágios de cristalização, estequiometria ou hidratação. Adicionalmente, os metais aparecem geralmente na forma solúvel e, quando insolúveis, na forma de óxidos, adsorbatos ou imobilizados em matéria orgânica. ${ }^{8}$

Além da matéria orgânica dissolvida ou particulada, os óxihidróxidos de ferro (Fe) e de manganês ( $\mathrm{Mn})$, os carbonatos e os sulfetos são as principais fases ligantes de metais nos sedimentos, além da fração particulada mais fina, capaz de realizar adsorção. ${ }^{9}$ Em ambientes anaeróbios, os sulfetos praticamente governam a especiação, biodisponibilidade e toxicidade dos metais. Desse modo, mesmo em ambientes muito impactados por efluentes domésticos e industriais, não será verificada uma toxicidade relativa a metais, se a concentração de sulfetos for bastante elevada. ${ }^{10-12}$

A formação dos sulfetos se dá em ambientes anaeróbios, pela ação de bactérias redutoras de sulfato (BRS), na presença de substâncias orgânicas, sejam elas de origem natural ou antropogênica. Esses micro-organismos têm a capacidade de mediar a transferência de elétrons entre os doadores (matéria orgânica) e os receptores (sulfa- 
tos), oxidando os primeiros e reduzindo quimicamente os últimos. ${ }^{13}$ Pode-se dizer que é na diagênese anaeróbia da matéria orgânica, acompanhada da redução do sulfato, que se formam os sulfetos de ferro. ${ }^{14} \mathrm{O}$ resultado desse processo é a mineralização parcial ou total do carbono e a sulfidização dos sedimentos, formando predominantemente os sulfetos de ferro e manganês, dada a abundância natural destes dois metais. ${ }^{15-17}$

Existe uma região ótima de formação dos sulfetos nos sedimentos, que é intermediária entre a interface sedimento-água e as porções mais profundas. Geralmente na superfície, verifica-se a presença de $\mathrm{O}_{2}$, $\mathrm{NO}_{3}{ }^{-}, \mathrm{Mn}$ (IV) e Fe (III), que funcionam como receptores de elétrons em detrimento ao $\mathrm{SO}_{4}{ }^{2-}$, com consequente minimização da produção de sulfeto. Em grandes profundidades, existe uma limitação em função da restrição na difusão dos íons $\mathrm{SO}_{4}^{2-}$, o que implica em uma menor disponibilidade deste substrato para a produção de sulfeto. ${ }^{17}$

Em ambientes fortemente influenciados por atividades antrópicas, como reservatórios de água de regiões metropolitanas, podem ser observados comportamentos bastante peculiares, como a ocorrência de concentrações consideráveis de sulfetos em porções sub-superficiais do sedimento $(2-4 \mathrm{~cm})$, seguida de regiões pobres em sulfetos e uma nova ocorrência dos sulfetos em porções mais profundas de tais sedimentos $(11-16 \mathrm{~cm}) .{ }^{18}$ Tal comportamento redox, nestes sedimentos impactados, pode ser atribuído às atividades bentônicas, que criam dutos nos sedimentos e propiciam a difusão de água contendo concentrações de oxigênio dissolvido relativamente maiores que os valores pré-existentes na água intersticial.

\section{A IMPORTÂNCIA DA MINERALIZAÇÃO DA MATÉRIA ORGÂNICA NA PRODUÇÃO DE SULFETOS}

Vários autores procuram apresentar modelos para explicar o tamponamento dos sedimentos aquáticos, principalmente os marinhos, sendo comum o ponto de vista de que a matéria orgânica usada nas reações químicas obedece à razão de Redfield, $\left(\mathrm{CH}_{2} \mathrm{O}\right)_{106}\left(\mathrm{NH}_{3}\right)_{16}\left(\mathrm{H}_{3} \mathrm{PO}_{4}\right)$, empiricamente definida a partir da observação da composição de diferentes tipos de plâncton e águas coletadas em oceanos. ${ }^{19}$ A degradação que ocorre na superfície dos sedimentos, a qual utiliza $\mathrm{O}_{2}$ e nitrato como receptores de elétrons, causa uma leve diminuição do $\mathrm{pH}$ das águas intersticiais, para valores em torno de 5 , com aumento na concentração de $\mathrm{CO}_{2}$ como resultado da degradação da matéria orgânica e incrementos nos valores de concentração de $\mathrm{Ca}^{2+}$ e alcalinidade, como consequência da dissolução do $\mathrm{CaCO}_{3} \cdot{ }^{20-23}$ Podem ser encontradas na literatura ${ }^{19,24}$ as equações envolvendo os receptores de elétrons normalmente presentes nos sedimentos, bem como as suas respectivas energias livre de Gibbs, na degradação da "molécula de Redfield".

$$
\begin{gathered}
\left(\mathrm{CH}_{2} \mathrm{O}\right)_{106}\left(\mathrm{NH}_{3}\right)_{16}\left(\mathrm{H}_{3} \mathrm{PO}_{4}\right)+138 \mathrm{O}_{2} \rightarrow \\
\rightarrow 106 \mathrm{CO}_{2}+16 \mathrm{HNO}_{3}+\mathrm{H}_{3} \mathrm{PO}_{4}+122 \mathrm{H}_{2} \mathrm{O} \\
\Delta \mathrm{G}^{0,}=-56.367,3 \mathrm{~kJ} \mathrm{~mol}^{-1} \\
\left(\mathrm{CH}_{2} \mathrm{O}\right)_{106}\left(\mathrm{NH}_{3}\right)_{16}\left(\mathrm{H}_{3} \mathrm{PO}_{4}\right)+236 \mathrm{MnO}_{2}+472 \mathrm{H}^{+} \rightarrow \\
\rightarrow 236 \mathrm{Mn}^{2+}+106 \mathrm{CO}_{2}+8 \mathrm{~N}_{2}+\mathrm{H}_{3} \mathrm{PO}_{4}+366 \mathrm{H}_{2} \mathrm{O} \\
\Delta \mathrm{G}^{0,}=-54.600,3 \mathrm{~kJ} \mathrm{~mol}^{-1}(\text { birnessita) } \\
\Delta \mathrm{G}^{0,}=-53.893,5 \mathrm{~kJ} \mathrm{~mol}^{-1} \text { (nsutita) } \\
\Delta \mathrm{G}^{0,}=-51.596,4 \mathrm{~kJ} \mathrm{~mol}^{-1} \text { (pirolusita) } \\
\left(\mathrm{CH}_{2} \mathrm{O}\right)_{106}\left(\mathrm{NH}_{3}\right)_{16}\left(\mathrm{H}_{3} \mathrm{PO}_{4}\right)+94,4 \mathrm{HNO}_{3} \rightarrow \\
\rightarrow 106 \mathrm{CO}_{2}+55,2 \mathrm{~N}_{2}+\mathrm{H}_{3} \mathrm{PO}_{4}+177,2 \mathrm{H}_{2} \mathrm{O} \\
\Delta \mathrm{G}^{0,}=-53.540,1 \mathrm{~kJ} \mathrm{~mol}^{-1} \\
\rightarrow 106 \mathrm{CO}_{2}+42,4 \mathrm{~N}_{2}+16 \mathrm{NH}_{3}+\mathrm{H}_{3} \mathrm{PO}_{4}+148,4 \mathrm{H}_{2} \mathrm{O} \\
\Delta \mathrm{G}^{0,}=-48.592,5 \mathrm{~kJ} \mathrm{~mol}^{-1}
\end{gathered}
$$

$$
\begin{gathered}
\left(\mathrm{CH}_{2} \mathrm{O}\right)_{106}\left(\mathrm{NH}_{3}\right)_{16}\left(\mathrm{H}_{3} \mathrm{PO}_{4}\right)+212 \mathrm{Fe}_{2} \mathrm{O}_{3}(\mathrm{ou} 424 \mathrm{FeOOH})+ \\
848 \mathrm{H}^{+} \rightarrow 424 \mathrm{Fe}^{2+}+106 \mathrm{CO}_{2}++16 \mathrm{NH}_{3}+\mathrm{H}_{3} \mathrm{PO}_{4}+ \\
530 \mathrm{H}_{2} \mathrm{O}\left(\mathrm{ou}_{7}+\mathrm{H}_{2} \mathrm{O}\right) \\
\Delta \mathrm{G}^{0,}=-24.914,7 \mathrm{~kJ} \mathrm{~mol}^{-1}\left(\text { hematita, } \mathrm{Fe}_{2} \mathrm{O}_{3}\right) \\
\Delta \mathrm{G}^{0,}=-23.501,1 \mathrm{~kJ} \mathrm{~mol}^{-1}(\text { goethita limonítica, FeOOH}) \\
\left(\mathrm{CH}_{2} \mathrm{O}\right)_{106}\left(\mathrm{NH}_{3}\right)_{16}\left(\mathrm{H}_{3} \mathrm{PO}_{4}\right)+53 \mathrm{SO}_{4}^{2-} \rightarrow \\
\rightarrow 106 \mathrm{CO}_{2}+16 \mathrm{NH}_{3}+53 \mathrm{~S}^{2-}+\mathrm{H}_{3} \mathrm{PO}_{4}+106 \mathrm{H}_{2} \mathrm{O} \\
\Delta \mathrm{G}^{0,}=-6.714,6 \mathrm{~kJ} \mathrm{~mol}^{-1} \\
\left(\mathrm{CH}_{2} \mathrm{O}\right)_{106}\left(\mathrm{NH}_{3}\right)_{16}\left(\mathrm{H}_{3} \mathrm{PO}_{4}\right) \rightarrow \\
\rightarrow 53 \mathrm{CO}_{2}+53 \mathrm{CH}_{4}+16 \mathrm{NH}_{3}+\mathrm{H}_{3} \mathrm{PO}_{4} \\
\Delta \mathrm{G}^{0,}=-6.184,5 \mathrm{~kJ} \mathrm{~mol}^{-1}
\end{gathered}
$$

A decomposição da matéria orgânica em ambientes aquáticos anaeróbios segue a sequência de hidrólise extracelular, fermentação e respiração de $\mathrm{CO}_{2} \cdot{ }^{25} \mathrm{~A}$ fermentação é uma das vias mais eficientes de transformação microbiológica da matéria orgânica aquática sedimentar, fornecendo substrato para os subsequentes processos anóxicos, responsáveis pela etapa final de degradação do carbono orgânico. ${ }^{26}$

Esta decomposição anaeróbia dos compostos orgânicos em sedimentos, a qual utiliza em menor escala os óxi-hidróxidos de ferro e manganês, e principalmente os sulfatos como receptores de elétrons, é acompanhada de um aumento na alcalinidade com a produção de $\mathrm{HCO}_{3}{ }^{-}, \mathrm{HS}^{-}, \mathrm{HPO}_{4}{ }^{2-}, \mathrm{FeS}_{2}, \mathrm{~N}$-amoniacal e precipitação de $\mathrm{CaCO}_{3}$, principalmente sob a forma de aragonita e calcita gerados biogenicamente. $\mathrm{O} \mathrm{CO}_{2}$ produzido nesta decomposição é o precursor do ânion bicarbonato, principal responsável pela alcalinidade..$^{20,21,23,27}$

É na etapa final de degradação da matéria orgânica que substâncias oxidantes, normalmente presentes em sedimentos eutróficos, passam a ser relevantes. O consumo destes oxidantes se dá em função da profundidade, seguindo uma ordem crescente de produção de energia livre de Gibbs por mol de carbono orgânico oxidado, obedecendo à sequência: $\mathrm{O}_{2}>$ óxidos de $\mathrm{Mn} \sim$ nitratos $>$ óxidos de $\mathrm{Fe}>$ sulfatos. Independentemente do oxidante utilizado, $\mathrm{CO}_{2}$ será gerado como um dos subprodutos. ${ }^{24}$

A mineralização de compostos orgânicos nos sedimentos chega a ocorrer com uma eficiência até 30 vezes superior à via que emprega o sulfato como receptor de elétrons. ${ }^{28,29}$ A oxidação por nitratos é mais efetiva com respeito à matéria orgânica mais lábil, localizada na superfície dos sedimentos de fundo, fornecendo alcalinidade pela formação de $\mathrm{CO}_{2}$, além de $\mathrm{N}_{2}$ e água. ${ }^{26}$ Devido à natureza destes últimos compostos e das características da degradação anaeróbia, esses processos terminais são mais lentos do que os primeiros. ${ }^{29}$

Após o consumo total destes receptores de elétrons, verifica-se a mineralização estritamente anaeróbia da matéria orgânica via metanogênese, nas regiões mais profundas da matriz. ${ }^{25,26,29,30}$

Os principais substratos da metanogênese são os acetatos, $\mathrm{CO}_{2}$ e $\mathrm{H}_{2}$, que são convertidos a $\mathrm{CH}_{4}$ e $\mathrm{CO}_{2},{ }^{31}$ por uma classe de microorganismos antigamente denominada como arqueobactérias, mas que atualmente recebeu um domínio à parte, o Archaea, sendo os seus integrantes chamados de arqueias, por não poderem ser enquadrados no domínio Bacteria, tampouco no Eukarya, dadas as suas especificidades genéticas. ${ }^{32}$ As arqueias metanogênicas podem ser subdivididas em dois grupos, as acetoclásticas e as hidrogenotróficas. As primeiras produzem metano e $\mathrm{CO}_{2}$ a partir da clivagem do ácido acético, enquanto que as últimas consomem o $\mathrm{H}_{2}$ e o $\mathrm{CO}_{2}$ gerado em etapas anteriores de degradação (acidogênese) formando metano e água. ${ }^{31}$

Nos sedimentos aquáticos, tanto a degradação aeróbia quanto a anaeróbia da matéria orgânica produzem $\mathrm{CO}_{2}$ e outras substâncias quimicamente reduzidas, dependendo do tipo de receptor de elétrons empregado. ${ }^{33}$ Portanto, o dióxido de carbono produzido em todos os níveis da degradação da matéria orgânica em sedimentos tem influ- 
ência direta sobre a alcalinidade destes ambientes, sendo o carbono inorgânico o mais forte sistema tamponante de águas naturais. ${ }^{34}$ Apesar do $\mathrm{pH}$ e da alcalinidade estarem relacionados, eles podem variar independentemente um do outro. ${ }^{20}$

O carbonato de cálcio, predominantemente sob a forma de calcita, é encontrado na maioria dos sedimentos aquáticos naturais e tem a sua solubilidade alterada em função da mineralização da matéria orgânica, com consequente produção de $\mathrm{CO}_{2}$. Bicarbonato é formado quando um excesso de $\mathrm{CO}_{2}$ dissolvido interage com a calcita, segundo a reação:

$$
\mathrm{CaCO}_{3}+\mathrm{CO}_{2}+\mathrm{H}_{2} \mathrm{O} \rightarrow 2 \mathrm{HCO}_{3}^{-}+2 \mathrm{Ca}^{2+}
$$

Desta forma, há um aumento na alcalinidade das águas intersticiais decorrente da produção de $\mathrm{CO}_{2}$ que leva à formação dos bicarbonatos, dissolvendo parte do $\mathrm{CaCO}_{3}$ depositado. ${ }^{21}$

O sulfeto solúvel produzido pela redução do sulfato, concomitantemente à oxidação de carbono orgânico, é difícil de ser detectado por conta da transformação dos óxi-hidróxidos de ferro sólidos em pirita sólida $\left(\mathrm{FeS}_{2}\right)$, notadamente em ambientes marinhos. ${ }^{23}$

$$
8 \mathrm{Fe}(\mathrm{OH})_{3}+15 \mathrm{HS}^{-}+\mathrm{SO}_{4}{ }^{2-}+17 \mathrm{H}^{+} \rightarrow 8 \mathrm{FeS}_{2}+28 \mathrm{H}_{2} \mathrm{O}
$$

Dentro deste contexto, é possível ainda afirmar que, em sedimentos onde houver abundância de sulfato e escassez de matéria orgânica, como os sedimentos marinhos, espera-se uma baixa concentração de sulfetos solúveis nas águas intersticiais, já que ocorrerá pouca sulfidização, pela falta de matéria a ser oxidada, e os sulfetos formados sofrerão precipitação. ${ }^{35} \mathrm{Em}$ águas naturais, quando em geral a concentração de sulfatos é mais baixa comparativamente à de matéria orgânica, se observa que na ausência de outros agentes oxidantes, a metanogênese é o processo predominante, já que haverá quantidade suficiente de ácidos orgânicos voláteis provenientes da etapa de acidogênese, que não sofreram oxidação pelos sulfatos e estarão disponíveis para serem convertidos a metano. ${ }^{36}$

$\mathrm{Na}$ interface entre a região de redução de sulfatos e a região de produção de metano, ocorrem dois fenômenos que podem ser distinguidos quanto ao fluxo de $\mathrm{H}_{2}$ : a metanogênese direta e a oxidação anaeróbia do metano (OAM), onde são propostos mecanismos de metanogênese reversa, os quais não são plenamente conhecidos. Admite-se que um consórcio de micro-organismos Archaea e bactérias redutoras de sulfato propicie um fluxo exergônico de $\mathrm{H}_{2}$, com consumo de $\mathrm{CH}_{4}$ e $\mathrm{SO}_{4}{ }^{2-30,37-40}$

Reversão da metanogênese hidrogenotrófica:

$$
\begin{gathered}
\mathrm{CH}_{4}+2 \mathrm{H}_{2} \mathrm{O} \rightarrow \mathrm{CO}_{2}+4 \mathrm{H}_{2}(\text { Archaea }) \\
\mathrm{SO}_{4}^{2-}+4 \mathrm{H}_{2}+\mathrm{H}^{+} \rightarrow \mathrm{HS}^{-}+4 \mathrm{H}_{2} \mathrm{O}(\mathrm{BRS}) \\
\mathrm{SO}_{4}^{2-}+\mathrm{CH}_{4} \rightarrow \mathrm{HCO}_{3}^{-}+\mathrm{HS}^{-}+\mathrm{H}_{2} \mathrm{O} \text { (processo global) }
\end{gathered}
$$

Formação de ácido acético por duas moléculas de metano:

$$
\begin{gathered}
2 \mathrm{CH}_{4}+2 \mathrm{H}_{2} \mathrm{O} \rightarrow \mathrm{CH}_{3} \mathrm{COOH}+4 \mathrm{H}_{2} \text { (Archaea) } \\
4 \mathrm{H}_{2}+\mathrm{SO}_{4}^{2-}+\mathrm{H}^{+} \rightarrow \mathrm{HS}^{-}+4 \mathrm{H}_{2} \mathrm{O} \text { (BRS) } \\
\mathrm{CH}_{4}+\mathrm{SO}_{4}^{2-} \rightarrow \mathrm{HCO}_{3}^{-}+\mathrm{HS}^{-}+\mathrm{H}_{2} \mathrm{O} \text { (processo global) }
\end{gathered}
$$

Reversão da metanogênese acetoclástica

$$
\mathrm{CH}_{4}+\mathrm{HCO}_{3}^{-} \rightarrow \mathrm{CH}_{3} \mathrm{COO}^{-}+\mathrm{H}_{2} \mathrm{O}(\text { Archaea })
$$

$$
\begin{gathered}
\mathrm{CH}_{3} \mathrm{COO}^{-}+\mathrm{SO}_{4}{ }^{2-} \rightarrow 2 \mathrm{HCO}_{3}^{-}+\mathrm{HS}^{-}(\mathrm{BRS}) \\
\mathrm{CH}_{4}+\mathrm{SO}_{4}{ }^{2-} \rightarrow \mathrm{HCO}_{3}^{-}+\mathrm{HS}^{-}+\mathrm{H}_{2} \mathrm{O} \text { (processo global) }
\end{gathered}
$$

A hipótese de uma metilogênese, onde sulfetos metilados produzidos por organismos oxidantes de metano e Archaea redutores de dióxido de carbono são transferidos às BRS, é outra proposta para a OAM, porém, ainda incipiente e sem maiores esclarecimentos quanto aos mecanismos..$^{40,41}$

Algumas substâncias reduzidas, produzidas na oxidação do carbono, podem ser reoxidadas, absorvidas ou precipitadas em etapas posteriores. ${ }^{20,30,31,33,36} \mathrm{O}$ metano gasoso, devido a sua baixa solubilidade no meio líquido, atinge com facilidade a zona de redução de sulfatos, ${ }^{35}$ sofrendo OAM.

Desta forma, é estabelecida uma competição pelo $\mathrm{H}_{2}$ produzido na degradação da matéria orgânica em etapas fermentativas preliminares, sendo que na presença de muito sulfato e pouco carbono a metanogênese seria prejudicada, uma vez que com altas concentrações de carbono comparativamente aos sulfatos, a metanogênese não sofreria competição pelo $\mathrm{H}_{2}$.

Da mesma forma que a matéria orgânica e os receptores de elétrons apresentam uma difusão pela matriz no sentido superfície - fundo, gerando reservatórios específicos destes oxidantes, os produtos mais voláteis resultantes da degradação da matéria orgânica, como $\mathrm{N}_{2}, \mathrm{NH}_{3}, \mathrm{H}_{2}, \mathrm{CH}_{4}$ e $\mathrm{CO}_{2}$, apresentam uma difusão reversa, ou seja, do fundo para a superfície, em função da sua solubilidade e do $\mathrm{pH}$, já que a amônia e o dióxido de carbono, por exemplo, apresentam maior ou menor afinidade com o meio líquido em função da atividade hidrogeniônica. Assim, dentro do sedimento, as áreas limítrofes dos reservatórios dos agentes oxidantes se tornam os lugares onde se verificam reações reversas de destacada relevância, como a já mencionada metanogênese reversa ou oxidação anaeróbia do metano (OAM).

Com relação à geração de alcalinidade com a OAM, esta última está intimamente ligada à produção de bicarbonato e bissulfeto, aumentando a alcalinidade e elevando o $\mathrm{pH}$ para valores em torno de $7,9 .^{20,36}$

$$
\mathrm{CH}_{4}+\mathrm{SO}_{4}{ }^{2-} \rightarrow \mathrm{HCO}_{3}^{-}+\mathrm{HS}^{-}+\mathrm{H}_{2} \mathrm{O}
$$

Além disso, pode-se verificar a liberação de fósforo e a metilação do mercúrio inorgânico, aumentando sobremaneira o potencial tóxico do sedimento. ${ }^{33}$

Em resumo, a mineralização aeróbia de matéria orgânica e a reoxidação anaeróbia de compostos reduzidos, como $\mathrm{NH}_{4}^{+}, \mathrm{Fe}^{2+}, \mathrm{Mn}^{2+}$, HS e $\mathrm{CH}_{4}$, tendem a baixar o $\mathrm{pH}$ e solubilizar $\mathrm{CaCO}_{3}$. No limite entre as regiões aeróbia-anaeróbia, o $\mathrm{pH}$ tende a um valor mínimo. $\mathrm{Na}$ região anaeróbia, a redução dos sulfatos e a dissolução/precipitação da calcita são os processos que mais influenciam no valor do $\mathrm{pH}$, o qual se mantém próximo da neutralidade. Na reoxidação anaeróbia do metano por sulfato, o consumo deste último tende a aumentar o $\mathrm{pH}$, mas a produção de sulfeto e bicarbonato tende a diminuí-lo, estabelecendo um equilíbrio com $\mathrm{pH}$ entre $6-8 .^{20,22}$

\section{LABILIDADE DOS SULFETOS DE FERRO}

Em relação aos metais, a redução dos óxidos de ferro e manganês proporciona um aumento na liberação destes elementos para as águas intersticiais; no caso de seus respectivos sulfatos, há uma diminuição na concentração dos metais solúveis devido à formação de sulfetos pouco solúveis. Consequentemente, quando há baixos teores de matéria orgânica biodegradável nos sedimentos (limitante), a taxa de conversão das substâncias oxidadas para reduzidas é menor. ${ }^{42}$ 
Áreas de solo com características sulfato-ácidas, susceptíveis à inundação e aos alagamentos por efeitos naturais de sazonalidade, formam ambientes anaeróbios intermitentes onde há a redução dos íons $\mathrm{Fe}$ (III) a $\mathrm{Fe}$ (II) com consequente aumento do $\mathrm{pH}$, segundo a reação: ${ }^{43}$

$$
\mathrm{Fe}_{8} \mathrm{O}_{8}(\mathrm{OH})_{6} \mathrm{SO}_{4}+22 \mathrm{H}^{+}+8 \mathrm{e}^{-} \leftrightarrows 8 \mathrm{Fe}^{2+}+\mathrm{SO}_{4}{ }^{2-}+14 \mathrm{H}_{2} \mathrm{O}
$$

Froelich e colaboradores apresentam uma reação de degradação da matéria orgânica de Redfield com redução de ferro, a qual igualmente consome prótons (Equação 5). ${ }^{24}$

As bactérias redutoras de ferro oxidam a matéria orgânica mais lábil como os acetatos. Esse ambiente também facilita a formação de sulfetos. ${ }^{43}$ Além disso, um aumento de $\mathrm{pH}$ por si já é responsável pelo aumento na adsorção dos metais nas partículas mais finas do sedimento, devido à diminuição na concorrência pelos sítios de ligação, entre $\mathrm{H}^{+}$e os cátions metálicos. ${ }^{44}$ Não só o $\mathrm{pH}$ é um indicador das condições ótimas para a produção de sulfetos, mas também o potencial redox $\left(\mathrm{E}_{\mathrm{H}}\right)$, sendo que a partir de valores menores do que - 120 $\mathrm{mV}$ já se tem um fator que propicia a redução de sulfato a sulfeto. ${ }^{12}$

Os sulfetos de ferro podem se apresentar sob as mais diferentes composições químicas e estruturais, dependendo da sua idade e do local onde se encontram, intercambiando-se com o passar do tempo. As espécies mais lábeis, provenientes de recente formação, são predominantemente a mackinawita $\left(\mathrm{FeS}\right.$, tetragonal) e a greigita $\left(\mathrm{Fe}_{3} \mathrm{~S}_{4}\right)$; a espécie mais estável formada apenas por $\mathrm{Fe}$ e $\mathrm{S}$ é a pirita, abundante em regiões de atividade vulcânica e hidrotermal. A labilidade da mackinawita é dada pela facilidade em se deslocar o elemento ferro do composto, substituindo-o por outro capaz de formar um sulfeto mais estável, imobilizando-o sob essa forma e liberando cátions Fe para o ambiente. ${ }^{45}$ Essa fonte de sulfetos reativos, se em maior quantidade com relação aos metais de transição presentes, pode imobilizar estes últimos na forma sólida, diminuindo drasticamente a sua toxicidade. ${ }^{46}$

Apesar de pouco mencionado, o ferro em excesso nos sedimentos também apresenta potencial tóxico às macrófitas aquáticas, causando pontos necróticos em folhas e formação de placas ferruginosas nas raízes, matando-as prematuramente. ${ }^{47}$

\section{SULFETOS VOLATILIZÁVEIS POR ACIDIFICAÇ̃̃O E METAIS EXTRAÍDOS SIMULTANEAMENTE - BREVE HISTÓRICO}

A partir da década de 1990, vários estudos começaram a ser conduzidos com o objetivo de se avaliar a toxicidade de substâncias orgânicas não iônicas nos sedimentos ${ }^{48}$ além da função dos sulfetos na imobilização e biodisponibilização de metais potencialmente tóxicos nessa mesma matriz. ${ }^{49-51}$

Uma atenção especial começou a ser dispensada à determinação dos sulfetos de ferro lábeis no sedimento, fase esta responsável por ser a fonte de sulfeto para a complexação dos demais metais com potencial contaminante. Estipulou-se então, para efeitos operacionais, uma classe chamada acid volatile sulfide (AVS) que são aqueles sulfetos capazes de se transformar em ácido sulfídrico $\left(\mathrm{H}_{2} \mathrm{~S}\right)$ e serem liberados do sedimento na forma gasosa, mediante acidificação do meio com ácido clorídrico $(\mathrm{HCl})$ na concentração final de $1 \mathrm{~mol} \mathrm{~L}^{-1}$ e a frio, sob purga de gás inerte. ${ }^{52} \mathrm{O}$ material restante desta extração é filtrado em membranas com porosidade de $0,45 \mu \mathrm{m}$ e se realiza, na fase líquida, a quantificação dos metais de interesse, caracterizando uma outra classe de espécies, chamada de simultaneously extracted metals (SEM). Acredita-se que aqueles metais ligados à fase sulfeto, bem como os adsorvidos em óxidos de ferro ou em carbono orgânico particulado são extraídos nesse processo. ${ }^{15,50,52}$

Tanto o AVS quanto o SEM ganharam várias traduções em portu- guês, sendo consagradas pelo uso aquelas que recebem a denominação de sulfetos volatilizáveis por acidificação (SVA) e metais extraídos simultaneamente (MES), respectivamente. Essa extração mais branda, assim como outros tipos de extração sequencial relatados na literatura, não é capaz de recuperar os metais ligados às estruturas de silicato e às formas geoquímicas ou minerais mais recalcitrantes da matriz, apresentando por isso uma boa indicação da biodisponibilidade destes metais às populações bentônicas ${ }^{4}$. No entanto, existem controvérsias neste sentido, uma vez que as espécies químicas que encerram os SVA, bem como os seus estados geomorfológicos, variam dependendo do histórico da matriz. Assim, sedimentos que apresentem tanto valores de concentração de SVA quanto de MES próximos podem apresentar toxicidades distintas, com respeito a metais, dada a complexidade e diversidade das interações sulfetos-metais existentes nos compostos aos quais os organismos bentônicos são expostos.

Di Toro e colaboradores ${ }^{49}$ foram pioneiros na aplicação da metodologia dos SVA para qualidade de sedimentos. Eles avaliaram o potencial tóxico de alguns sedimentos aquáticos contendo SVA, após a dopagem com cádmio e exposição, em ambiente controlado, de duas espécies de anfípodos, que são microcrustáceos marinhos.

Os sulfetos presentes em amostras-controle dopadas com cádmio, nas quais não estão presentes os organismos-alvo, foram convertidos a $\mathrm{H}_{2} \mathrm{~S}$ pela adição de $\mathrm{HCl}$ a frio, arrastados via purga com $\mathrm{N}_{2} \mathrm{e}$ borbulhados em um primeiro frasco lavador contendo solução de biftalato de potássio, com pH igual a 4, visando a retenção de cloretos. Ainda em linha no sistema, $\mathrm{o}_{2} \mathrm{~S}$ emergente do primeiro frasco lavador foi conduzido a dois frascos lavadores posicionados em série e preenchidos com uma solução de nitrato de prata. Os sulfetos volatilizados foram precipitados na forma de $\mathrm{Ag}_{2} \mathrm{~S}$. Este procedimento permitiu tanto a quantificação dos SVA, quanto da concentração de cádmio disponibilizada.

Três importantes constatações foram feitas neste trabalho: na primeira, em um sistema sem organismos, foi observado que após adições sucessivas de uma solução de cádmio ao sistema sedimento - água do mar - ocorria um aumento na concentração do metal no sedimento, enquanto que na água intersticial a concentração deste metal permanecia abaixo do limite de detecção.

Após um número elevado de adições, percebeu-se que a concentração do metal na água aumentava de forma rápida, enquanto que no sedimento permanecia praticamente inalterada, mostrando que havia sorção de cádmio pelo sedimento e que o metal só começava a se acumular na água intersticial após uma saturação da fase sólida sulfídica.

A segunda constatação ocorreu ao se tentar a quantificação potenciométrica dos sulfetos no sistema. Neste procedimento, antes de se atingir a saturação da fase sólida, verificou-se que os sinais para o analito estavam abaixo do limite de detecção da técnica. Porém, após as adições de cloreto de cádmio, percebeu-se a formação de um fino sólido amarelo de $\mathrm{CdS}$ na superfície. Esta observação sugere que o sulfeto, antes na forma de FeS sólido, passa para a forma de CdS sólido, após uma reação de deslocamento, dada a menor solubilidade do último comparativamente ao primeiro. Uma titulação comprovou facilmente esta hipótese.

Finalmente, a terceira constatação do estudo ocorreu durante a realização de testes de avaliação da toxicidade de amostras de três diferentes sedimentos condicionados em água do mar, os quais receberam uma quantidade conhecida dos organismos-alvo. Em tais sedimentos foi observado que, quando a concentração molar dos SVA era inferior à de cádmio extraído simultaneamente, se verificava toxicidade crônica aos organismos-alvo, ao passo que quando a concentração molar de SVA era predominante sobre a do metal, não se verificava toxicidade crônica. Este estudo também sugeriu que seria possível estender para outros metais de interesse ambiental as observações por eles relatadas utilizando-se $\mathrm{Cd}$. 
Muitos metais podem formar sulfetos insolúveis em condições anaeróbias, mas pelo uso, ocorrência e potencial de contaminação foram eleitos níquel $(\mathrm{Ni})$, zinco $(\mathrm{Zn})$, cádmio $(\mathrm{Cd})$, chumbo $(\mathrm{Pb})$ e cobre $(\mathrm{Cu})$ como os principais metais responsáveis pela toxicidade de sedimentos. Em estudos específicos, mercúrio $(\mathrm{Hg})$, prata $(\mathrm{Ag})$ e cromo $(\mathrm{Cr})$ podem também ser avaliados, além do semi-metal arsênio (As). ${ }^{9,51}$

\section{Métodos de determinação de SVA e MES}

A coleta das amostras é determinante na qualidade do resultado final. Devem ser minimizadas as perdas de sulfeto, seja por volatilização ou por exposição prolongada ao ar, o que ocasionaria a ocorrência de oxidações.

A montagem originalmente concebida e amplamente utilizada até hoje para se quantificar MES e SVA consiste de um sistema extrator de purga-e-aprisionamento (purge and trap) onde se submete a amostra de sedimento a um ataque de $\mathrm{HCl}$ a frio, sob purga de gás inerte mais agitação mecânica, produzindo $\mathrm{H}_{2} \mathrm{~S}$ que é recolhido em uma solução de retenção de sulfetos, a qual pode ter a sua composição variada em função do método de quantificação de sulfeto escolhido. ${ }^{52}$ Gravimetria com íons prata, ${ }^{53}$ espectrofotometria pelo método do azul de metileno ${ }^{54-56}$ ou, ainda, a determinação potenciométrica usando eletrodo íon seletivo (EIS) $)^{57,58}$ são os métodos mais citados na literatura.

Há variações no método de extração, as quais podem seguir o mesmo princípio do original ${ }^{59}$ ou utilizar a técnica dos filmes finos. ${ }^{58,60}$

$\mathrm{Na}$ Figura 1, pode ser visto um esquema de montagem para o sistema extrator de SVA e MES, utilizado para estudos de potencial tóxico de sedimentos na bacia do Rio Jundiaí - SP. ${ }^{61}$

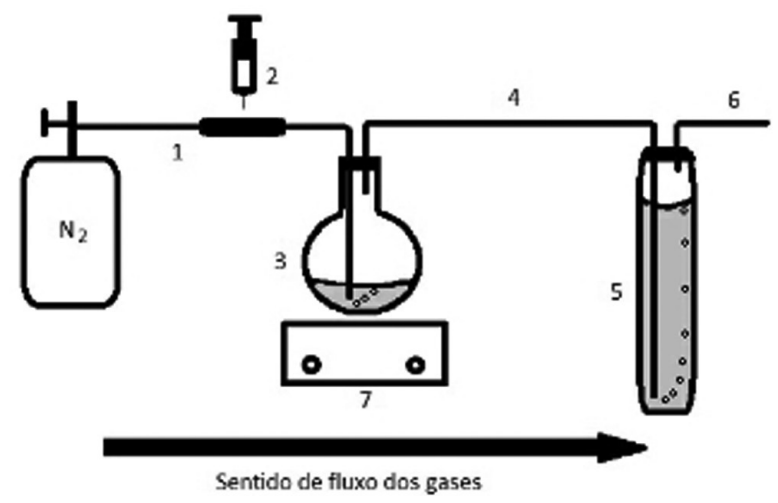

Figura 1. Representação esquemática do sistema extrator para SVA e MES. (1) entrada do gás de purga no sistema; (2) seringa para injeção de $\mathrm{HCl}$ no septo posicionado na linha de gás; (3) balão de extração; (4) conexão entre o balão de extração e o frasco lavador, por onde fluirá o $\mathrm{H}_{2} \mathrm{~S}$ recém-gerado; (5) frasco lavador contendo tampão básico antioxidante, responsável por reter os sulfetos; (6) saída do sistema para o ambiente; (7) agitador magnético

É muito comum encontrar na literatura a recomendação da utilização de dois frascos absorvedores em série. Contudo, a experiência destes autores mostra que não é detectado sulfeto em um segundo frasco absorvedor quando este é instalado, e que a utilização de um único frasco, conforme apresentado na Figura 1, propicia a obtenção de valores adequados de recuperação. Desta forma, a partir do momento em que esteja disponível um conjunto de dados históricos que atestem o bom desempenho do sistema de extração, torna-se recomendável a operação com apenas um frasco de retenção de $\mathrm{H}_{2} \mathrm{~S}$, economizando reagentes e gerando menor quantidade de resíduos.

Independentemente dos sulfetos, os MES são determinados tomando-se a solução ácida da lixiviação dos sedimentos, restante da análise dos SVA, após a mesma ser filtrada em membrana com porosidade de $0,45 \mu \mathrm{m}$. Os teores dos cinco metais de interesse são comumente quantificados por técnicas de espectrometria atômica, como absorção atômica por chama ou forno de grafite, ou emissão atômica por plasma indutivamente acoplado.

Tanto os valores de SVA quanto os de MES são expressos em base seca, mas analisados em base úmida, de onde decorre a necessidade de uma etapa adicional de determinação da umidade da matriz, ou a chamada perda por evaporação forçada (PEF), que se dá em uma estufa a $103-105{ }^{\circ} \mathrm{C}$ até massa constante. Esta determinação segue um procedimento análogo ao que é empregado na determinação de sólidos totais (ST), presentes em amostras de caráter ambiental e sanitário. Secagens a temperaturas mais baixas $\left(60{ }^{\circ} \mathrm{C}\right)$ podem ser mais conservativas com relação às características da amostra, mas levarão mais tempo para serem processadas. ${ }^{62}$

\section{A relação matemática entre SVA e MES}

Como os cinco metais classicamente estudados em abordagens que envolvem associações com sulfeto, que são o $\mathrm{Cd}, \mathrm{Cu}, \mathrm{Ni}, \mathrm{Pb}$ e Zn, se apresentam todos sob a forma divalente nos sedimentos (cátions de carga elétrica 2+), e os sulfetos são igualmente divalentes (ânions de carga elétrica 2-), se realiza um balanço de massas entre a quantidade de sulfetos lábeis existentes e disponíveis para complexação e a soma da quantidade dos metais potencialmente tóxicos, resultando em um critério para a qualidade do sedimento, que matematicamente pode ser escrito como: 9

$$
\frac{\sum M E S}{S V A}=\frac{\sum\left(M E S_{N i}+M E S_{Z n}+M E S_{C d}+M E S_{P b}+M E S_{C u}\right)}{S V A}
$$

Se tanto os MES quanto os SVA são expressos na mesma unidade de concentração, convencionalmente $\mu \mathrm{mol} \mathrm{g}{ }^{-1}$, pode-se dizer que, quando a razão MES/SVA é $\leq 1,0$, há predominância ou no mínimo equivalência da fase sulfeto sobre a fase metal e, dada a alta afinidade entre elas, é de se esperar que todos esses metais estejam imobilizados sob a forma de sulfeto metálico sólido no sedimento, tornando-se não disponíveis à biota. Desta forma, se espera que as concentrações de metais nas águas intersticiais da matriz não atinjam níveis deletérios aos seres vivos e que não exista toxicidade devido aos metais, nesse caso. ${ }^{9}$

Porém, se a razão MES/SVA é > 1,0 há grande chance, tanto do sedimento quanto da sua água intersticial apresentarem valores de concentração de metais em patamares capazes de causar toxicidade aos organismos a ele associados.

Atualmente, a maioria dos autores prefere expressar essa relação não mais como uma razão, e sim como uma subtração, de modo que a expressão se torna:

$$
\sum M E S-S V A=\left(\sum M E S_{N i, Z n, C d, P b, C u}\right)-S V A
$$

Neste caso, quando MES - SVA $\leq 0$, não se espera toxicidade por parte dos metais; se MES - SVA > 0, são esperados efeitos agudos sobre a biota. ${ }^{9,10,49,52}$

Expressar a relação entre MES e SVA como uma razão apresenta duas desvantagens: a primeira diz respeito ao fato de que quando valores muito baixos de sulfeto são comparados com valores relativamente altos de metais, o número resultante é extremamente alto e não diz nada quanto à quantidade de metais que estaria disponível à biota. Em segundo lugar, refinamentos do cálculo levando em conta outras fases ligantes são difíceis de serem realizados. ${ }^{9}$

Em suma, quando os sulfetos superarem estequiometricamente 
os metais, provavelmente estes últimos estarão apresentando concentrações dentro de níveis seguros para a biota, tanto no sedimento quanto na água intersticial. Caso contrário, os metais poderão representar riscos significativos, caso não exista outra fase ligante controlando a sua biodisponibilização. Os óxidos e hidróxidos de ferro e manganês dificilmente existem em ambientes anaeróbios e fortemente sulfídricos, mais profundos, o que limita a importância destas espécies químicas às primeiras camadas do sedimento. Neste contexto, a matéria orgânica passa a ter grande relevância, já que depois dos sulfetos, ela é a principal fase ligante dos metais e está presente mesmo em ambientes anaeróbicos. Por esta razão, principalmente nos casos em que se tem MES > SVA, é que se adiciona uma variável à expressão, tornando-a: ${ }^{9}$

$$
\frac{\left[\left(\sum M E S\right)-S V A\right]}{f_{O C}}
$$

sendo que $\mathrm{f}_{\mathrm{OC}}$ corresponde à fração percentual em massa de carbono orgânico presente no sedimento.

Sedimentos que apresentam uma concentração de MES superior à dos SVA, ainda assim podem não apresentar toxicidade à biota, se o carbono orgânico presente for capaz de atenuar ou mesmo cancelar esses efeitos via complexação, tornando os metais não biodisponíveis.

Quando esse excesso de MES normalizado pelo carbono orgânico apresentar valores menores do que $130 \mu \mathrm{mol} \mathrm{g} \mathrm{gC}^{-1}$, considera-se que há baixo risco de toxicidade devido aos metais estudados. Se os valores normalizados estiverem na faixa entre 130-3000 $\mu \mathrm{mol}$ $\mathrm{g}_{\mathrm{OC}}{ }^{-1}$, pode haver toxicidade à biota. Por fim, para valores maiores do que $3000 \mu \mathrm{mol} \mathrm{g}_{\mathrm{OC}}{ }^{-1}$, efeitos biológicos adversos, como redução no crescimento, na reprodução e no tempo de vida, são esperados. ${ }^{63}$

Outra vantagem em se expressar a relação entre MES e SVA como uma diferença é que se pode saber quanto de sulfeto cada metal irá demandar para o controle da sua biodisponibilidade. Pela avaliação da magnitude das constantes dos produtos de solubilidade dos referidos sulfetos, é possível estimar qual metal será primeiramente imobilizado, bem como se poderá haver deslocamentos. ${ }^{64} \mathrm{~A}$ ordem de solubilidade dos sulfetos metálicos de interesse ambiental é: FeS $>\mathrm{NiS}>\mathrm{ZnS}>\mathrm{CdS}>\mathrm{PbS}>\mathrm{CuS} .{ }^{54}$ Os sulfetos de níquel (millerita $\mathrm{NiS}$, heazlewoodita $-\mathrm{Ni}_{2} \mathrm{~S}_{3}$ e vaesita $-\mathrm{NiS}_{2}$ ), cobre (covellita $-\mathrm{CuS}$ e calcocita $-\mathrm{Cu}_{2} \mathrm{~S}$ ) e mercúrio (cinábrio $-\mathrm{HgS}$ ) ${ }^{62-65}$ não são destruídos pela extração dos SVA, empregando-se $\mathrm{HCl}$ a frio: a recuperação destes metais enquanto MES se deve à detecção daquele estoque que se encontra interagido com outra fase ligante, como a matéria orgânica, por exemplo. ${ }^{9}$

\section{Mecanismos de interação metal - sedimento}

Existem matrizes em que se pode identificar a presença de vários metais potencialmente tóxicos, como $\mathrm{Cu}, \mathrm{Zn}, \mathrm{Pb}, \mathrm{Ni}$ e $\mathrm{Cd}$, ocorrendo ao mesmo tempo, com alta correlação entre si, revelando um tipo de contaminação advinda de fontes múltiplas, pela variedade de metais, mas com um comportamento diagenético similar. Em outros termos, há respostas físico-químicas equivalentes destes elementos quanto aos fenômenos de dissolução, precipitação, recristalização, compactação etc., nos processos deposicionais, durante e após a litificação. ${ }^{66}$ Por outro lado, há estudos mais específicos onde se avalia a relação entre a presença concomitante de sulfetos e de metais menos comuns como, por exemplo, o rênio $(\mathrm{Re})$, já que este também apresenta a tendência de formar um sulfeto sólido estável (rheniita, $\left.\mathrm{ReS}_{2}\right) \cdot{ }^{67}$ Contudo, via de regra, além dos cinco metais mais comuns já relatados, os que mais aparecem como objeto de estudo ambiental são a prata, o cromo e o mercúrio. Alguns detalhes sobre esses elementos serão aqui descritos.
A prata (Ag), para ser admitida no cálculo dos MES, deve ter a sua concentração dividida à metade, por uma razão estequiométrica, já que o sólido formado tem a fórmula $\mathrm{Ag}_{2} \mathrm{~S}$. Devido a seu baixo valor da constante do produto de solubilidade $\left(5,5 \times 10^{-51}\right)$, o critério para se avaliar prata no sedimento é meramente qualitativo: onde houver quantidades mensuráveis de sulfeto lábil, admite-se que não existe prata disponível em quantidades importantes para causar toxicidade. A prata só poderá ser novamente biodisponiblilizada a partir da oxidação dos sulfetos ou, quando baixíssimas quantidades de $\mathrm{Ag}(\mathrm{I})$ são adsorvidas em FeS e se deparam com altas concentrações de mercaptanas, formando-se tiolatos de prata com pequena cadeia, solúveis e passíveis de assimilação pelas células. ${ }^{68}$

Para efeitos de biorremediação de solos, íons prata podem ser utilizados para deslocar todos os cinco metais de seus respectivos sulfetos, liberando-os para serem lixiviados em meio ácido e separados da matriz sólida. $\mathrm{O}$ efeito da prata não é meramente de agente deslocador de equilíbrio químico, mas age também como catalisador de processos bioquímicos realizados por bactérias ativas no ciclo biogeoquímico do enxofre e do ferro. ${ }^{69}$

Por analogia, se a presença de sulfetos pode ser utilizada como indicador de quantidades seguras de prata, já que a sua solubilidade nessa situação seria de $2,2 \times 10^{-17} \mathrm{~mol} \mathrm{~L}^{-1}$, a mesma regra deveria valer para o mercúrio, que apresenta uma constante do produto de solubilidade igual a $1,6 \times 10^{-54}$ e solubilidade de $1,6 \times 10^{-27} \mathrm{~mol} \mathrm{~L}^{-1}$, que é dez ordens de magnitude menor do que a da prata. No entanto, o mercúrio, um metal que apresenta um ciclo biogeoquímico complexo, ${ }^{70-73}$ apresenta particularidades que tornam esta avaliação bastante intrincada.

O mercúrio presente nos sedimentos pode se ligar a sulfetos, à matéria orgânica, ou ainda a compostos orgânicos sulfurados, migrando entre essas fases, em função das condições ambientais. A tendência do mercúrio é de se concentrar mais nos sedimentos do que na coluna de água, mesmo em locais onde haja maior oxigenação, ficando claro que, neste caso, outras fases ligantes além daquela representada pelos sulfetos apresentam papel relevante na sua imobilização. ${ }^{74} \mathrm{Um}$ excesso de sulfetos pode levar à biodisponibilização do mercúrio, originalmente sob a forma de cinábrio $(\mathrm{HgS})$, tornando-o acessível à biota, em função da formação dos polissulfetos $\mathrm{Hg}\left(\mathrm{HS}^{2-}\right)$ ou $\mathrm{Hg}\left(\mathrm{S}_{2}{ }^{2-}\right)$, e não como $\mathrm{Hg}^{2+}$. ${ }^{75-77}$

As condições mais apropriadas para se formar os sulfetos e imobilizar o mercúrio são as mesmas capazes de promover a sua metilação, transformando-o em sua espécie mais tóxica, o metilmercúrio $\left(\mathrm{CH}_{3} \mathrm{Hg}^{+}\right){ }^{78}$

Com relação ao cromo $(\mathrm{Cr})$, não é possível a formação de um sulfeto de cromo no ambiente. ${ }^{79}$ Tal espécie química é obtida apenas em condições especiais, associadas à manufatura do aço, como resultado da mistura de reagentes no estado sólido, em temperaturas elevadas. ${ }^{80} \mathrm{~A}$ química do cromo no ambiente se restringe às suas duas principais espécies, $\mathrm{Cr}$ (VI) e $\mathrm{Cr}$ (III). O Cr (VI) é o estado altamente oxidado, mais solúvel e comprovadamente tóxico e cancerígeno, ${ }^{81}$ havendo vários estudos que comprovam seus efeitos sobre os seres vivos. Por sua vez, o Cr (III) é uma espécie de baixa solubilidade e de efeito tóxico duvidoso. Nos artigos onde é relatada a toxicidade do cromo, a espécie Cr (III) é citada como relativamente segura e estável, do ponto de vista ambiental. ${ }^{82}$

No ambiente, os sulfetos lábeis têm a capacidade de, facilmente, reduzir o $\mathrm{Cr}$ (VI) a $\mathrm{Cr}$ (III), formando enxofre elementar e $\mathrm{Cr}(\mathrm{OH})_{3}$, sendo esse último considerado não tóxico, de acordo com o entendimento vigente. Portanto, os SVA também regulam a biodisponibilidade do cromo, não pela formação de sulfetos insolúveis, mas pela redução química deste a um estado de oxidação que leva à formação de hidróxido pouco solúvel. ${ }^{55,83}$ Os minerais ferrosos são capazes de catalisar a redução do $\mathrm{Cr}$ (VI) pelos sul- 
fetos, em uma reação de segunda ordem. A mesma ação redutora pode ser atribuída ao enxofre elementar formado e que atua em etapas mais tardias, onde as nanopartículas do enxofre elementar, produzidas pela própria reação, adsorvem os sulfetos e aumentam a sua eficiência na promoção da redução química do cromo. Assim, só quando uma quantidade razoável de enxofre for produzida é que esse efeito começará a ser importante. ${ }^{84}$

Admite-se ainda que, sob condições anóxicas e em meios ricos em matéria orgânica, propícios à formação dos SVA, a forma $\mathrm{Cr}$ (VI) é termodinamicamente instável, esperando-se encontrar apenas a forma $\mathrm{Cr}$ (III). ${ }^{81,85} \mathrm{~A}$ reoxidação do $\mathrm{Cr}$ (III) a $\mathrm{Cr}$ (VI) só é possível em condições especiais, onde haja grande oxigenação, $\mathrm{H}_{2} \mathrm{O}_{2}$, Fe e Mn geralmente na forma de óxidos jovens e amorfos, além de pequenas quantidades de matéria orgânica, numa cinética bastante lenta. ${ }^{86} \mathrm{Uma}$ grande quantidade de matéria orgânica inviabilizaria o processo, mesmo em ambientes bastante oxidantes, pois esta complexaria o $\mathrm{Cr}$ (III) inibindo uma possível oxidação para o estado VI. ${ }^{81}$

Substâncias orgânicas liberadas pelo sistema radicular da vegetação, em sedimentos de áreas alagadas, formam um ambiente redutor, podendo facilitar a conversão do sulfato a sulfeto, propiciando a redução do $\mathrm{Cr}$ (VI) a $\mathrm{Cr}$ (III). ${ }^{87}$

As condições ambientais nas quais se verifica a formação de SVA, são as mesmas que fazem com que o cromo seja encontrado na forma de espécies químicas de $\mathrm{Cr}$ (III).

\section{IMPORTÂNCIA DOS ENSAIOS DE TOXICIDADE}

As determinações químicas de sulfetos, metais e matéria orgânica, principalmente naqueles casos onde foi levantada a hipótese de contaminação das águas intersticiais, carecem de confirmação biológica para um diagnóstico mais preciso e correto. Além de análises químicas, ensaios de toxicidade com organismos vivos devem ser realizados para se obter informações mais precisas sobre o grau de impactação da matriz. É recomendável levar em conta não somente a especiação do contaminante, mas também o tipo de organismo-alvo que está sendo usado no estudo. Dieta, particularidades morfológicas, estágio na cadeia alimentar, modo e profundidade de obtenção de alimento são variáveis a serem consideradas. ${ }^{88}$

Os ensaios de toxicidade são realizados em águas e sedimentos, sempre se escolhendo espécies animais e vegetais que sejam bastante sensíveis às alterações do meio, bem como obtenham energia necessária para a manutenção do seu metabolismo a partir deste. Neste contexto, possíveis contaminantes têm o seu efeito deletério avaliado. Os testes podem ser de conotação aguda ou crônica, fornecendo importantes informações quanto ao risco ambiental a que se está sujeito, bem como balizando tomadas de decisão no sentido de conservação ou remediação de áreas impactadas.

Os referidos ensaios também apresentam algumas fontes de incertezas: a escolha de organismos teste que não interajam de forma adequada com a matriz, pode levar a desvios do método. Da mesma forma, a característica peculiar de alguns organismos bentônicos no que diz respeito a concentrar mais do que apenas um metal, pode causar anomalias nos resultados obtidos, com relação àqueles que bioacumulam um único metal. Os hábitos alimentares dos organismos empregados nos testes de toxicidade também são importantes. Um exemplo provém dos organismos filtradores que se alimentam de partículas de sedimento, que podem liberar metais em contato com a acidez do seu trato intestinal, ocasionando tanto toxicidade como má formação fisiológica.

Assim sendo, os estudos de toxicidade mais conclusivos acerca do potencial tóxico de uma matriz são aqueles realizados com mais do que apenas uma espécie de organismo-alvo. ${ }^{89}$ Outra questão é a adaptação destes organismos à contaminação: processos de bioirri- gação daqueles indivíduos que constroem tubos intercomunicantes, entre as fases sedimento - água, podem amenizar o potencial tóxico do sedimento, tornando-os adaptáveis ao meio. ${ }^{9}$ Há ainda organismos que desenvolvem mecanismos enzimáticos específicos de desintoxicação para se defender dos efeitos dos sulfetos. ${ }^{13}$

Os sulfetos livres isoladamente podem também apresentar alta toxicidade, mesmo para as bactérias redutoras de sulfato (BRS), que suportam quantidades limitadas de seu próprio produto metabólico. A toxicidade devido aos metais e aos sulfetos, portanto, merece ser considerada não somente de forma sinérgica, mas também de forma independente. ${ }^{46}$

\section{LIMITAÇÕES AO USO DO MÉTODO DE SVA E MES}

Apesar de ser uma estratégia bastante útil, o uso de SVA - MES na avaliação do potencial tóxico de sedimentos apresenta, como toda técnica, algumas limitações.

Globalmente, um dos aspectos que mais chama a atenção com relação ao uso de MES e SVA para se estimar a toxicidade, é que apenas se considera o sulfeto como fase protetora e conservadora dos sedimentos com respeito à toxicidade dos metais, mas pouco já foi estudado sobre a relação inversa: a toxicidade dos sulfetos, a qual não é desprezível, sendo controlada pela fase metálica.

Há três vertentes fundamentais a serem consideradas com relação ao sulfeto no ambiente aquático: sua toxicidade natural, a atenuação da toxicidade de metais pela sua presença e o efeito sobre a toxicidade de outras substâncias, modificando o comportamento dos organismos.

Os sulfetos livres apresentam uma toxicidade maior do que a da amônia não ionizada, em termos de concentração (a USEPA estabelece o limite de $2 \mu \mathrm{g} \mathrm{L}^{-1}$ para $\mathrm{H}_{2} \mathrm{~S}$, enquanto que para $\mathrm{NH}_{3}$, é de $35 \mu \mathrm{g}$ $\mathrm{L}^{-1}$, quando se avalia a toxicidade em águas doces superficiais e águas salinas). ${ }^{13}$ Contudo, estas comparações representam uma abordagem complexa, pois podem apresentar variações em função da escolha dos organismos teste que são utilizados. O ferro é classicamente o seu principal ligante, mas o zinco também tem um papel relevante na retenção dos sulfetos, já que o sulfeto de zinco, principalmente nas camadas mais expostas do sedimento, é mais refratário à oxidação do que o de ferro ou manganês, funcionando como um conservador ou estabilizador de sulfetos..$^{90}$

Seus efeitos nas macrófitas aquáticas consistem em decomposição radicular, redução do crescimento e eventualmente a morte, nos casos onde os valores de concentrações estiverem na faixa entre 10-1400 $\mu \mathrm{mol} \mathrm{L} \mathrm{L}^{-1}$. Nos invertebrados, podem causar bloqueio da respiração anaeróbia pela inibição da enzima citocromo $\mathrm{C}$ oxidase, na altura das mitocôndrias, na faixa entre $0,7-33 \mu \mathrm{mol} \mathrm{L}{ }^{-1} \cdot{ }^{47}$

Apesar da concentração dos sulfetos em água doce ser tipicamente menor do que em água salgada, a tolerância dos organismos que vivem nos rios e lagos é igualmente inferior. ${ }^{13}$

A instrumentação utilizada na extração dos SVA deve passar por constantes testes de recuperação, com o intuito de se verificar vazamentos de $\mathrm{H}_{2} \mathrm{~S}$, que levam à obtenção de teores subestimados de SVA. São esperadas recuperações da ordem de $87 \%{ }^{53}$ a $91 \%$ ou superior ${ }^{56,91}$ dependendo da técnica de quantificação e da concentração do analito utilizado nestes ensaios.

O risco de oxidação dos sulfetos da amostra, quando esta já se encontra no extrator, é menor do que no momento da coleta no campo. Após a acidificação do sedimento, a oxidação do $\mathrm{H}_{2} \mathrm{~S}$ liberado é lenta, além de fortemente dependente da concentração de radicais hidroxila $(\bullet \mathrm{OH})$, motivo pelo qual é possível sentir o seu odor no ambiente até com certa persistência, ajudando na identificação de vazamentos. Estudos em que se utiliza ar ao invés de nitrogênio como gás de arraste confirmam essa hipótese, onde a espécie mais rapidamente oxidável, 
o íon bissulfeto $\left(\mathrm{HS}^{-}\right)$não está presente em quantidades apreciáveis neste $\mathrm{pH}$, e sim a espécie $\mathrm{H}_{2} \mathrm{~S}$ dissolvida. ${ }^{56}$

Muita controvérsia está envolvida no universo dos SVA, tanto no que se refere à forma de preparação da amostra quanto à interpretação dos resultados. Cooper e Morse ${ }^{65}$ deixam claro que a análise de toxicidade a partir do procedimento para extração de SVA, usando $\mathrm{HCl}$ $6 \mathrm{~mol} \mathrm{~L}^{-1}$ a frio, poderia subestimar o potencial tóxico dessa matriz, já que os sulfetos de ferro, cádmio, chumbo e zinco são solúveis e disponibilizados por esse ataque ácido, mas o mesmo não ocorre com os sulfetos de mercúrio, níquel e cobre, que necessitariam sofrer digestão com ácido nítrico. Os autores sugerem, portanto, que não só os SVA contribuiriam para a biodiponibilidade dos metais, mas também os demais sulfetos.

Outros autores já consideram que, caso procedimentos mais drásticos fossem utilizados na extração, haveria o risco de se extrair aqueles metais presentes em formas mais insolúveis e menos lábeis, em função da destruição oxidativa dos sulfetos a eles associados. Isso acarretaria uma superestimação do teor de metais, mas sem a quantificação dos sulfetos correspondentes, podendo resultar em um alto valor teórico de toxicidade por metais, que na realidade não se verificaria. ${ }^{9}$

Morse e Rickard ${ }^{46}$ destacam que os fatores controladores dos teores de SVA presentes nos sedimentos podem sofrer influências sazonais, geológicas, e morfológicas. Nos ambientes favoráveis à formação dos SVA, chamados de regiões euxínicas, que são as águas estagnadas, com pouca comunicação para outros corpos d'água, concomitantemente anaeróbias e onde a presença de formas de vida superiores é desfavorecida, os sulfetos se encontram próximos à superfície dos sedimentos, numa faixa entre 4 e $6 \mathrm{~cm}$, admitindo-se que a $20 \mathrm{~cm}$ não mais se encontrariam os SVA. Além disso, pode-se evidenciar o efeito da sazonalidade no inverno, onde a predominância de baixas temperaturas ocasiona uma menor formação de sulfetos e, portanto, diminui o efeito amenizador da toxicidade dos metais por conta destes.

As variações sazonais na concentração dos sulfetos em regiões de clima temperado ${ }^{16}$ é um fato que parece não ser claramente evidenciado em regiões tropicais, onde as temperaturas são mais elevadas e apresentam menor amplitude entre as estações do ano. ${ }^{91} \mathrm{~A}$ contextualização dos resultados obtidos na relação MES - SVA deve, portanto, levar em conta a sazonalidade, já que predominantemente na literatura se verifica que nas estações mais quentes há uma maior produção dos SVA, devido principalmente ao metabolismo das BRS, responsáveis pela sulfidização dos sedimentos..$^{92}$ A quantidade de carbono orgânico que é produzida (produção primária), tanto em ambiente aeróbio quanto anaeróbio, afeta a produção dos sulfetos. Portanto, a área de estudo deve ser investigada em diferentes épocas do ano, para uma maior certeza do potencial tóxico frente à complexação de metais. ${ }^{15}$

Na Tabela 1 podem ser vistos valores típicos de SVA e MES em sedimentos aquáticos brasileiros. ${ }^{61,93-98}$

$\mathrm{Na}$ Tabela 2 são apresentados valores típicos de SVA e MES encontrados em diferentes partes do mundo, em locais sob as mais diversas influências antrópicas. ${ }^{14,57,66,99-101}$

Com relação ainda à mineralogia, Morse e Rickard ${ }^{46}$ afirmam que a dinâmica química dos SVA é de difícil entendimento, já que sua constituição pode ser bastante variada. São sólidos compostos predominantemente por sulfetos de ferro, como a mackinawita ( $\mathrm{FeS}$ tetragonal), greigita $\left(\mathrm{Fe}_{3} \mathrm{~S}_{4}\right.$ cúbico), troilita ( $\mathrm{FeS}$ hexagonal), pirrotitas ( $\mathrm{Fe}_{1-\mathrm{x}} \mathrm{S}$ hexagonal), pirita $\left(\mathrm{FeS}_{2}\right.$ cúbico) e marcasita $\left(\mathrm{FeS}_{2}\right.$ ortorrômbico), com destaque para os dois primeiros. Embora a toxicidade de sedimentos contendo metais e sulfetos seja diminuída na presença de SVA, esse efeito é temporário. Como a concentração dos metais é em nível de traço, mesmo para ambientes contaminados, o que realmente acontece é que, ao invés da formação direta do sulfeto metálico,
Tabela 1. Valores típicos de SVA e MES em sedimentos aquáticos brasileiros

\begin{tabular}{lccc}
\hline Local & SVA $\left(\mu \mathrm{mol} \mathrm{g}^{-1}\right)$ & MES $\left(\mu \mathrm{mol} \mathrm{g}^{-1}\right)$ & Ref. \\
\hline $\begin{array}{l}\text { Estuário - Rio Sergipe } \\
\text { (SE) (área impactada) }\end{array}$ & $4,3-17,2$ & $0,3-0,5$ & 93 \\
$\begin{array}{l}\text { Mangue - Baía de Guanabara } \\
\text { (RJ) (área impactada) }\end{array}$ & $0,07-18,79$ & 0,167 & 94 \\
$\begin{array}{l}\text { Estuário - Baía de Guanabara } \\
\text { (RJ) (área impactada) }\end{array}$ & $4,04-18,4$ & $5,31-6,42$ & 95 \\
$\begin{array}{l}\text { Reservatório - Rio Grande } \\
\text { (SP) (área impactada) }\end{array}$ & $0,74-80,83$ & 32,92 & 96 \\
$\begin{array}{l}\text { Mangue - Baía de Camamu } \\
\text { (BA) (área preservada) }\end{array}$ & 23,57 & 4,31 & 97 \\
$\begin{array}{l}\text { Rio Irai (PR) } \\
\text { (área de baixo impacto) }\end{array}$ & 11,0 & --- & 98 \\
$\begin{array}{l}\text { Jusante ETE - Rio Iguaçu } \\
\text { (PR) (área impactada) }\end{array}$ & 570,5 & --- & 98 \\
$\begin{array}{l}\text { Foz - Rio Jundiaí (SP) } \\
\text { (área impactada) }\end{array}$ & $7,80-9,77$ & $2,78-3,73$ & 61 \\
$\begin{array}{l}\text { Várzea - Rio Jundiaí (SP) } \\
\text { (área impactada) }\end{array}$ & $2,74-5,51$ & $1,55-2,66$ & 61 \\
$\begin{array}{l}\text { Foz - Ribeirão Piraí (SP) } \\
\text { (área de baixo impacto) }\end{array}$ & $1,90-3,70$ & $1,11-1,69$ & 61 \\
\hline
\end{tabular}

ocorre a adsorção e/ou coprecipitação na formação da mackinawita. Quando a mackinawita, com o passar do tempo, se transforma em pirita, esses metais adsorvidos e/ou enclausurados são novamente disponibilizados para o meio líquido, principalmente em ambientes marinhos e costeiros (como manguezais), onde a concentração de enxofre é muito maior do que nos ambientes aquáticos continentais ou de água doce. A remoção desses metais por parte da pirita varia com a concentração destes, bem como sua afinidade com a nova matriz. Portanto, embora seja relativamente simples medir SVA (sulfetos metaestáveis), a interpretação dos resultados pode ser controversa. Uma alternativa talvez fosse analisar a remoção realizada pela pirita, sulfeto mais estável.

Com relação aos MES, a quantificação dos metais, tanto em sedimentos quanto em águas intersticiais, deve ser feita obedecendo a rigorosos critérios analíticos de qualidade, respeitando-se as figuras de mérito de cada técnica. Em escala nacional, mesmo laboratórios certificados não necessariamente mostram proficiência neste tipo de análise, sabidamente em água, mas também com prováveis falhas para outros tipos de matrizes mais complexas. ${ }^{102}$

Outras fontes de contaminação que não os metais ficam fora desta análise que utiliza os parâmetros MES e SVA. ${ }^{6}$ Os testes de toxicidade podem chamar a atenção para esse aspecto, em situações onde não se espera potencial tóxico para a matriz (MES < SVA), mas esta é verificada mesmo assim, denotando a presença de outros agentes que o modelo não contempla. ${ }^{103}$ Além disso, o modelo é muito bom para prever toxicidade aguda, mas não contempla os possíveis efeitos causados por bioacumulação. ${ }^{104}$ As transições de fase sólida dos sulfetos de ferro, que de mackinawita e greigita passam a pirita, podem causar uma redisponibilização dos metais coprecipitados nessa reorganização estrutural, ${ }^{51}$ mas não necessariamente, já que outras fases ligantes podem ser formadas nessas novas condições. ${ }^{5,66}$ Efeitos antagônicos, aditivos ou sinérgicos, bem como a biomagnificação, não são contemplados pelo modelo. ${ }^{9}$

\section{CRITÉRIOS DA QUALIDADE DE SEDIMENTOS}

A classificação da qualidade dos sedimentos preconizada pela USEPA baseia-se na quantificação dos MES e SVA nos sedimentos, 
Tabela 2. Valores típicos de SVA e MES em sedimentos aquáticos ao redor do mundo

\begin{tabular}{|c|c|c|c|}
\hline Local & SVA $\left(\mu \mathrm{mol} \mathrm{g} \mathrm{g}^{-1}\right)$ & $\operatorname{MESS}\left(\mu \mathrm{mol} \mathrm{g}^{-1}\right)$ & Ref. \\
\hline $\begin{array}{l}\text { Baía Jinzhou, mar Bohai } \\
\text { (China) (fundição) }\end{array}$ & $3,0-126$ & $2,9-374$ & 14 \\
\hline $\begin{array}{l}\text { Porto Belledune, baía Chal- } \\
\text { eur (Canadá) (fundição, fab. } \\
\text { fertilizantes) }\end{array}$ & $5,5-102$ & $1,9-18,4$ & 14 \\
\hline $\begin{array}{l}\text { Enseada Foundry, foz rio } \\
\text { Hudson (EUA) (fab. baterias) }\end{array}$ & $0,40-64,6$ & $0,20-779$ & 14 \\
\hline $\begin{array}{l}\text { Riacho Bear, Porto de Bal- } \\
\text { timore (EUA) (doméstico e } \\
\text { industrial) }\end{array}$ & $0,40-304$ & $0,64-31,0$ & 14 \\
\hline $\begin{array}{l}\text { Pântano salgado, baía Buz- } \\
\text { zards (EUA) (metalurgia) }\end{array}$ & $0,44-419$ & $0,73-31,8$ & 14 \\
\hline $\begin{array}{l}\text { Lago Steilacoom, Washing- } \\
\text { ton (EUA) (uso de algicidas } \\
-\mathrm{Cu} \text { ) }\end{array}$ & $0,02-5,65$ & $0,60-3,91$ & 14 \\
\hline $\begin{array}{l}\text { Hidrobacia Keweenaw, } \\
\text { Michigan (EUA) (mineração } \\
\text { de } \mathrm{Cu} \text { ) }\end{array}$ & $0,006-11,6$ & $0,36-174$ & 14 \\
\hline $\begin{array}{l}\text { Riacho Turkey, Missouri } \\
\text { (EUA) (refugo de mineração) }\end{array}$ & $28,1-78,2$ & $47,6-94,5$ & 14 \\
\hline $\begin{array}{l}\text { Baixo Rio Missouri (EUA) } \\
\text { (doméstico e industrial) }\end{array}$ & $2,2-20,2$ & $0,40-2,14$ & 57 \\
\hline $\begin{array}{l}\text { Delta do Rio Zhu (China) } \\
\text { (densamente poluído) }\end{array}$ & $0,72-59,01$ & $0,99-26,86$ & 66 \\
\hline $\begin{array}{l}\text { Baía Portman (Espanha) } \\
\text { (refugo de mineração) }\end{array}$ & $47,2-510,7$ & $16,0-144$ & 99 \\
\hline $\begin{array}{l}\text { Riacho Trace, região de xisto } \\
\text { (EUA) (área preservada) }\end{array}$ & $0,01-0,07$ & $3,7-4,0$ & 100 \\
\hline $\begin{array}{l}\text { Riacho Begley, região de } \\
\text { xisto (EUA) (área preservada) }\end{array}$ & $0,02-1,82$ & $3,2-5,5$ & 100 \\
\hline $\begin{array}{l}\text { Riacho Cove, região de xisto } \\
\text { (EUA) (área preservada) }\end{array}$ & $0,01-0,02$ & $1,3-2,8$ & 100 \\
\hline $\begin{array}{l}\text { Riacho Mill, região de } \\
\text { calcário (EUA) (área preser- } \\
\text { vada) }\end{array}$ & $<0,01$ & $0,4-0,8$ & 100 \\
\hline $\begin{array}{l}\text { Rio Begej (Sérvia) (domésti- } \\
\text { co e industrial) }\end{array}$ & $4,3-7,1$ & $5,2-13,8$ & 101 \\
\hline $\begin{array}{l}\text { Rio Danúbio (Sérvia) (do- } \\
\text { méstico e industrial) }\end{array}$ & $10,2-11,2$ & $5,5-7,9$ & 101 \\
\hline
\end{tabular}

bem como metais disponíveis nas águas intersticiais. Os valores-guia da qualidade dos sedimentos (VGQS) referem-se ao equilíbrio de partição para a fase sólida, ao passo que para as águas intersticiais, têm-se os valores-guias de qualidade dos sedimentos das unidades tóxicas da água intersticial (VGUTAI). ${ }^{105}$

Uma combinação dos valores de MES, SVA e ensaios de toxicidade, resultam em três níveis qualitativos: aceitável (risco desprezível à biota), incerto (possível risco à biota) e não aceitável (risco iminente à biota, implicando na necessidade de remediações). ${ }^{9}$

Resumidamente, na Tabela 3 podem ser vistos os usos de SVA e MES no que diz respeito aos valores-guia de qualidade dos sedimentos (VGQS).

Apesar de alguns insucessos no uso dos SVA e MES na avaliação da toxicidade de sedimentos, os casos em que essa ferramenta foi útil e apropriada é muitas vezes maior. Além disso, atualmente os estudos de toxicidade não avaliam somente essas duas variáveis, mas também os VGUTAI e as frações metálicas fracamente ligadas, confirmando os VGQS empíricos, compondo os níveis de causa-efeito como threshold effects level (TEL), probable effects level (PEL) e severe effects level (SEL), ou ainda o effects range low (ERL) e o effects range medium (ERM). ${ }^{106}$

O método que utiliza os ensaios de toxicidade, aliados às análises de MES, SVA e avaliação de água intersticial para se determinar um critério de qualidade para sedimentos, apesar de bastante completo, pode apresentar algumas falhas. A coleta de amostra, etapa sempre crítica e fundamental, seja de água ou de sedimentos, é uma das principais fontes de erros. A perda do sulfeto por oxidação ou mesmo volatilização no momento da amostragem é um evento que merece atenção. Além disso, o acondicionamento e a preservação das amostras devem ser feitos de forma criteriosa, para manutenção do sulfeto. ${ }^{103}$

A própria natureza das amostras de caráter ambiental é sujeita a variâncias naturais, fazendo com que as médias das concentrações medidas de MES e SVA variem, podendo em alguns casos extremos chegar a ordem de $30 \% .^{54}$

\section{CONSIDERAÇÕES FINAIS}

Estudos que levem em consideração os parâmetros físicos (granulometria), químicos (MES, SVA, matéria orgânica, demais fases ligantes) e toxicológicos (testes de toxicidade), tanto na água quanto nos sedimentos, podem não abranger todos os aspectos da questão, mas podem mimetizar com sucesso ecossistemas aquáticos naturais. A interação intercompartimentos é bastante complexa e

Tabela 3. VGQS baseados em determinações de SVA, MES e $\mathrm{f}_{\text {oc }}$. Adaptada da ref. 9

\begin{tabular}{ll}
\hline Relação entre MES, SVA e $\mathrm{f}_{\mathrm{OC}}$ & Previsão de efeitos biológicos
\end{tabular}

$\begin{array}{ll}{\left[\frac{\left(\sum M E S\right)-S V A}{f_{O C}}\right]<130 \mu \mathrm{mol} \mathrm{g}^{-1}} & \text { baixo risco de efeitos biológicos adversos devido a } \mathrm{Cd}, \mathrm{Cu}, \mathrm{Pb}, \mathrm{Ni} \mathrm{e} \mathrm{Zn} \\ 130 \mu \mathrm{mol} \mathrm{g}{ }_{\circ c}{ }^{-1}<\left[\frac{\left(\sum M E S\right)-S V A}{f_{O C}}\right]<3000 \mu \mathrm{mol} \mathrm{g}_{\circ \mathrm{c}}{ }^{-1} & \text { podem haver efeitos biológicos adversos devido a } \mathrm{Cd}, \mathrm{Cu}, \mathrm{Pb}, \mathrm{Ni} \mathrm{e} \mathrm{Zn}\end{array}$

$\left[\frac{\left(\sum M E S\right)-S V A}{f_{O C}}\right]>3000 \mu \mathrm{mol} \mathrm{goc}{ }^{-1}$

efeitos biológicos adversos devido aCd, $\mathrm{Cu}, \mathrm{Pb}$, Ni e $\mathrm{Zn}$ são esperados

SVA $>0,0$

não haverá efeitos biológicos adversos devido à $\mathrm{Ag}, \mathrm{Hg}$ ou ao $\mathrm{Cr}$

O uso de $\left[\frac{\left(\sum M E S\right)-S V A}{f_{O C}}\right]$, quando $S V A \cong 0,0$ 
dinâmica, o que demanda vários estudos de confirmação e aprimoramento dos critérios de qualidade para águas e sedimentos. Além de fenômenos naturais ou artificiais de ressuspensão das partículas, normalmente motivadas por navegação e atividades aquáticas, também os organismos bentônicos fazem da região superficial dos sedimentos, chamada de zona biologicamente ativa, uma área de mistura, podendo contribuir para com os fluxos na interface sedimento/coluna d'água. Processos de dragagem de sedimentos expõem o material a um ambiente oxidante, propiciando a transformação de sulfetos em sulfatos, num processo que leva à geração de um meio ácido, aumentando a disponibilidade de alguns metais. No Brasil já há uma legislação vigente específica a esse respeito que utiliza os VGQS empíricos (TEL e PEL para ambientes de águas doces e ERL e ERM para águas salinas e salobras) não havendo uso ainda para o VGUTAI. No âmbito federal podem ser citadas a Resolução CONAMA No. 344/2004, ${ }^{107}$ que estabelece as diretrizes gerais e os procedimentos mínimos para a avaliação do material a ser dragado em águas jurisdicionais brasileiras, e dá outras providências, e também a Resolução CONAMA No. 357/2005, ${ }^{108}$ que estabelece que, quando a metodologia analítica disponível for insuficiente para quantificar as concentrações das espécies químicas de interesse em águas, os sedimentos e/ou biota poderão ser investigados.

\section{REFERÊNCIAS}

1. Manahan, S. E.; Industrial ecology: environmental chemistry and hazardous waste, $1^{\text {st }}$ ed., CRC: Lewis, 1999.

2. Allen, H. E.; Hall, R. H.; Brisbin, T. D.; Environ. Sci. Technol. 1980, 14, 411.

3. Berry, W. J.; Hansen, D. J.; Mahony, J. D.; Robson, D. L.; Di Toro, D. M.; Shipley, B. P.; Rogers, B.; Corbin, J. M.; Boothman, W. S.; Environ. Toxicol. Chem. 1996, 15, 2067.

4. Larner, B. L.; Palmer, A. S.; Seen, A. J.; Townsend, A. T.; Anal. Chim. Acta 2008, 608, 147.

5. van der Geest, H. G.; Paumen, M. L.; Sci. Tot. Environ. 2008, 406, 419.

6. Araújo, R. P. A.; Botta-Paschoal, C. M. R.; Silvério, P. F.; Almeida, F. V.; Rodrigues, P. F.; Umbuzeiro, G. A.; Jardim, W. F.; Mozeto, A. A.; Environ. Toxicol. Chem. 2006, 25, 581.

7. Stronkhorst, J.; Brils, J.; Batty, J.; Coquery, M.; Gardner, M.; Mannio, J.; O’Donnell, C.; Steenwijk, J.; Frintrop, P.; Discussion document on sediment monitoring guidance for the EU Water Framework Directive, Version 2, EU Water Framework Directive expert group on AMPS: Deltares (NL), 2004.

8. Das, A. K.; Chakraborty, R.; Cervera, M. L.; De La Guardia, M.; Talanta 1995, 42, 1007.

9. USEPA - United States Environmental Protection Agency; Procedures for the derivation of equilibrium partitioning sediment benchmarks (ESBs) for the protection of benthic organisms: Metal mixtures (cadmium copper, lead nickel, silver, and zinc), EPA-600-R-02-011, Office of Research and Development: Washington DC, 2005.

10. Mozeto, A. A.; Umbuzeiro, G. A.; Jardim, W. F.; Métodos de coleta, análises físico-químicas e ensaios biológicos e ecotoxicológicos de sedimentos de água doce, $1^{\text {a }}$ ed., Cubo Multimídia: São Carlos, 2006.

11. Scheffer, E. W.; Sodré, F. F.; Grassi, M. T.; Quim. Nova 2007, 30, 332.

12. Marcussen, H.; Dalsgaard, A.; Holm, P. E.; Environ. Pollut. 2008, 155, 41.

13. Wang, F.; Chapman, P. M.; Environ. Toxicol. Chem. 1999, 18, 2526.

14. Hansen, D. J.; Mahony, J. D.; Berry, W. J.; Benyi, S. J.; Corbin, J. M.; Pratt, S. D.; Di Toro, D. M.; Abel, M. B.; Environ. Toxicol. Chem. 1996, 15, 2126.

15. Di Toro, D. M.; Mahony, J. D.; Hansen, D. J.; Berry, W. J.; Environ. Toxicol. Chem. 1996, 15, 2168.

16. Rickard, D.; Morse, J. W.; Mar. Chem. 2005, 97, 141.
17. Yin, H. B.; Fan, C. X.; Ding, S. M.; Zhang, L.; Li, B.; Bull. Environ. Contam. Toxicol. 2008, 80, 351.

18. Mozeto, A. A.; Silvério, P. F.; Soares, A.; Sci. Total Environ. 2001, 266, 135.

19. Redfield, A. C.; Am. Sci. 1958, 46, 206.

20. Soetaert, K.; Hofmann, A. F.; Middelburg, J. J.; Meysman, F. J. R.; Grennwood, J.; Mar. Chem. 2007, 106, 380.

21. Gehlen, M.; Mucci, A.; Boudreau, B.; Geochim. Cosmochim. Acta 1999, 63, 2763.

22. Wu, F. C.; Qing, H. R.; Wan, G. J.; Tang, D. G.; Huang, R. G.; Cai, Y. R.; Water, Air, Soil Pollut. 1997, 99, 381.

23. Mucci, A.; Sundby, B.; Gehlen, M.; Arakaki, T.; Zhong, S.; Silverberg, N.; Deep-Sea Res. Pt. II 2000, 47, 733.

24. Froelich, P. N.; Klinkhammer, G. P.; Bender, M. L.; Luedtke, N. A.; Heath, G. R.; Cullen, D.; Dauphin, P.; Hammond, D.; Hartman, B.; Maynard, V.; Geochim. Cosmochim. Acta 1979, 43, 1075.

25. Brüchert, V.; Arnosti, C.; Mar. Chem. 2003, 80, 171.

26. Abell, J.; Laverman, A. M.; van Cappellen, P.; Biogeochemistry 2009, 94, 13.

27. Abril, G.; Etcheber, H.; Le Hir, P.; Bassoullet, P.; Boutier, B.; Frankignoulle, M.; Limnol. Oceanogr. 1999, 44, 1304

28. Pallud, C.; Meile, C.; Laverman, A. M.; Abell, J.; van Cappellen, P.; Mar. Chem. 2007, 106, 256.

29. Canavan, R. W.; Slomp, C. P.; Jourabchi, P.; van Cappellen, P.; Laverman, A. M.; van der Berg, G.; Geochim. Cosmochim. Acta 2006, 70, 2836.

30. Fossing, H.; Ferdelman, T. G.; Berg, P.; Geochim. Cosmochim. Acta 2000, 64, 897.

31. Chernicaro, C. A. L.; Princípios do tratamento biológico de águas residuárias - volume 5: reatores anaeróbios, $1^{\text {a }}$ ed., DESA/UFMG: Belo Horizonte, 1997.

32. Forterre, P.; Orig. Life Evol. Biosph. 2010, 40, 151.

33. Matthews, D. A.; Effler, S. W.; Driscoll, C. T.; O`Donell, S. M.; Matthews, C. M.; Limnol. Oceanogr. 2008, 53, 743.

34. Driscoll, C.; Effler, S. W.; Doerr, S. M.; Environ. Sci. Technol. 1994, 28, 1211.

35. Wallmann, K.; Aloisi, G.; Haeckel, M.; Obzhirov, A.; Pavlova, G.; Tischenko, P.; Geochim. Cosmochim. Acta 2006, 70, 3905.

36. Ogrinc, N.; Hintelmann, H.; Eckley, C.; Lojen, S.; Hydrobiologia 2003, 494, 207.

37. Valentine, D. L.; Reeburgh, W. S.; Environ. Microbiol. 2000, 2, 477.

38. Valentine, D. L.; Blanton, D. C.; Reeburgh, W. S.; Arch. Microbiol. 2000, 174, 415

39. Hallam, S. J.; Putnam, N.; Preston, C. M.; Detter, J. C.; Rokshar, D.; Richardson, P. M.; DeLong, E. F.; Science 2004, 305, 1457.

40. Caldwell, S. L.; Laidler, J. R.; Brewer, E. A.; Eberly, J. O.; Sandborgh, S. C.; Colwell, F. S.; Environ. Sci. Technol. 2008, 42, 6791.

41. Moran, J. J.; Beal, E. J.; Vrentas, J. M.; Orphan, V. J.; Freeman, K. H.; House, C. H.; Environ. Microbiol. 2008, 10, 162.

42. Lesven, L.; Gao, Y.; Billon, G.; Leermakers, M.; Ouddane, B.; Fischer, J.C.; Baeyens, W.; Sci. Total Environ. 2008, 407, 447.

43. Burton, E. D.; Bush, R. T.; Sullivan, L. A.; Johnston, S. G.; Hocking, R. K.; Chem. Geo. 2008, 253, 64.

44. Mahony, J. D.; Di Toro, D. M.; Gonzalez, A. M.; Curto, M.; Dilg, M.; De Rosa, L. D.; Sparrow, L. A.; Environ. Toxicol. Chem. 1996, 15, 2187.

45. Cooper, D. C.; Morse, J. W.; Aquat. Geochem. 1999, 5, 87.

46. Morse, J. W.; Rickard, D.; Environ. Sci. Technol. 2004, 38, $131 \mathrm{~A}$.

47. van der Welle, M. E. W.; Cuppens, M.; Lamers, L. P. M.; Roelofs, J. G. M.; Environ. Toxicol. Chem. 2006, 25, 1592.

48. Di Toro, D. M.; Zarba, C. S.; Hansen, D. J.; Berry, W. J.; Swartz, R. C.; Cowan, C. E.; Pavlou, S. P.; Allen, H. E.; Thomas, N. A.; Paquin, P. R.; Environ. Toxicol. Chem. 1991, 10, 1541.

49. Di Toro, D. M.; Mahony, J. D.; Hansen, D. J.; Scott, K. J.; Hicks, M. B.; Mayr, S. M.; Redmond, M. S.; Environ. Toxicol. Chem. 1990, 9, 1487. 
50. Ankley, G. T.; Mattson, V. R.; Leonard, E. N.; West, C. W.; Bennett, J. L.; Environ. Toxicol. Chem. 1993, 12, 315.

51. Morse, J. W.; Luther III, G. W.; Geochim. Cosmochim. Acta 1999, 63, 3373.

52. Allen, H. E.; Fu, G.; Deng, B.; Environ. Toxicol. Chem. 1993, 12, 1441.

53. Peterson, G. S.; Ankley, G. T.; Leonard, E. N.; Environ. Toxicol. Chem. 1996, 15, 2147.

54. Nizoli, E. C.; Luiz-Silva, W.; Quim. Nova 2009, 32, 365.

55. Graham, A. M.; Wadhawan, A. R.; Bouwer, E. J.; Environ. Toxicol. Chem. 2009, 28, 471.

56. Gonzalez, A. M.; Environ. Toxicol. Chem. 2002, 21, 980.

57. Echols, K. R.; Brumbaugh, W. G.; Orazio, C. E.; May, T. W.; Poulton, B. C.; Peterman, P. H.; Arch. Environ. Contam. Toxicol. 2008, 55, 161.

58. Rearick, M. S.; Gilmour, C. C.; Heyes, A.; Mason, R. P.; Environ. Toxicol. Chem. 2005, 24, 3043

59. Leonard, E. N.; Cotter, A. M.; Ankley, G. T.; Environ. Toxicol. Chem. 1996, 15,1479 .

60. Roulier, J. L.; Tusseau-Vuillemin, M. H.; Coquery, M.; Geffard, O.; Garric, J.; Chemosphere 2008, 70, 925.

61. Fagnani, E.; Tese de Doutorado, Universidade Estadual de Campinas, Brasil, 2009.

62. Desrosiers, M.; Gagnon, C.; Masson, S.; Martel, L.; Babut, M. P.; Sci. Total Environ. 2008, 389, 101.

63. Besser, J. M.; Brumbaugh, W. G.; Ivey, C. D.; Ingersoll, C. G.; Moran, P. W.; Arch. Environ. Contam. Toxicol. 2008, 54, 557.

64. Hansen, D. J.; Berry, W. J.; Mahony, J. D.; Boothman, W. S.; Di Toro, D. M.; Robson, D. L.; Ankley, G. T.; Ma, D.; Yan, Q.; Pesch, C .E.; Environ. Toxicol. Chem. 1996, 15, 2080.

65. Cooper, D. C.; Morse, J. W.; Environ. Sci. Technol. 1998, 32, 1076.

66. Li, F.; Wen, Y.-M.; Zhu, P.-T.; Bull. Environ. Contam. Toxicol. 2008, 81, 90.

67. Chappaz, A.; Gobeil, C.; Tessier, A.; Geochim. Cosmochim. Acta 2008 , $72,6027$.

68. Bell, R. A.; Kramer, J. R.; Environ. Toxicol. Chem. 1999, 18, 9.

69. Chen, S.-Y.; Lin, J.-G.; J. Hazard. Mater. 2009, 161, 893.

70. Silva, G. S.; Jardim, W. F.; Fadini, P. S.; Sci. Total Environ. 2006, 368, 189

71. Jardim, W. F.; Bisinoti, M. C.; Fadini, P. S.; Silva, G. S.; Aquat. Geochem. 2010, 16, 267.

72. Silva, G. S.; Jardim, W. F.; Fadini, P. S.; J. Braz. Chem. Soc. 2009, 20, 1549.

73. Silva, G. S.; Bisinoti, M. C.; Fadini, P. S.; Magarelli, G.; Jardim, W. F.; Fostier, A-.H.; J. Braz. Chem. Soc. 2009, 20, 1127.

74. Chibunda, R. T.; Pereka, A. E.; Tungaraza, C.; Phys. Chem. Earth 2008, 33,738 .

75. Morel, F. M. M.; Kraepiel, A. M. L.; Amyot, M.; Annu. Rev. Ecol. Syst. 1998, 29, 543

76. Benoit, J. M.; Gilmour, C. C.; Mason, R. P.; Heyes, A.; Environ. Sci. Technol. 1999, 33, 951.

77. Belzile, N.; Lang, C.-Y.; Chen, Y.-W.; Wang, M.; Sci. Total Environ. 2008, 405, 226.

78. Liu, G.; Cai, Y.; Kalla, P.; Scheidt, D.; Richards, J.; Scinto, L. J.; Gaiser, E.; Appleby, C.; Environ. Sci. Technol. 2008, 42, 1954.

79. He, P.-J.; Xiao, Z.; Shao, L.-M.; Yu, J.-Y; Lee, D.-J.; J. Hazard. Mater. 2006, $B 137,1385$.

80. Oikawa, K.; Mitsui, H.; Ohtani, H.; Ishida, K.; ISIJ Int. 2000, 40, 182; Ryan, M. P.; Williams, D. E.; Chater, R. J.; Hutton, B. M.; Mcphail, D. S.; Nature 2002, 415, 770; Pan, T. J.; Gesmundo, F.; Niu, Y.; Corros. Sci. 2007, 49, 1362
81. Berry, W. J.; Boothman, W. S.; Serbst, J. R.; Edwards, P. A.; Environ. Toxicol. Chem. 2004, 23, 2981.

82. Besser, J. M.; Brumbaugh, W. G.; Kemble, N. E.; May, T. W.; Ingersoll, C. G.; Environ. Sci. Technol. 2004, 38, 6210 .

83. Becker, D. S.; Long, E. R.; Proctor, D. M.; Ginn, T. C.; Environ. Toxicol. Chem. 2006, 25, 2576.

84. Lan, Y.; Deng, B.; Kim, C.; Thornton, E. C.; Geochemical Transactions (2007), doi: 10.1186/1467-4866-8-4.

85. MDE - Maryland Department of Environment; Water quality analyses of chromium in the Inner Harbor/Northwest Branch and Bear Creek Portions of Baltimore Harbor in Baltimore City and Baltimore County, Maryland, U.S. EPA: Baltimore, 2004.

86. Martello, L.; Fuchsman, P.; Sorensen, M.; Magar, V.; Wenning, R. J.; Arch. Environ. Contam. Toxicol. 2007, 53, 337; Magar, V. S.; Martello, L.; Southworth, B.; Fuchsman, P.; Sorensen, M.; Wenning, R. J.; Sci. Total Environ. 2008, 394, 103.

87. Zazo, J. A.; Paull, J. S.; Jaffe, P. R.; Environ. Pollut. 2008, 156, 29.

88. Lee, B. G.; Lee, J. S.; Luoma, S. N.; Choi, H. J.; Koh, C. H.; Environ. Sci. Technol. 2000, 34, 4517.

89. De Lange, H. J.; De Haas, E. M.; Maas, H.; Peeters, E. T. H. M.; Chemosphere 2005, 61, 1700.

90. Liber, K.; Call, D. J.; Markee, T. P.; Schmude, K. L.; Balcer, M. D.; Whiteman, F. W.; Ankley, G. T.; Environ. Toxicol. Chem. 1996, 15, 2113.

91. Silvério, P. F.; Fonseca, A. L.; Botta-Paschoal, C. M. R.; Mozeto, A. A.; Aquat. Ecosyst. Health Manage. 2005, 8, 313.

92. Manahan, S. E.; Environmental Chemistry, $7^{\text {th }}$ ed.; CRC: Lewis, 2000.

93. Alves, J. P. H.; Passos, E. A.; Garcia, C. A. B.; J. Braz. Chem. Soc. 2007, 18,748 .

94. Farias, C. O.; Hamacher, C.; Wagener, A. L. R.; Campos, R. C.; Godoy, J. M.; J. Braz. Chem. Soc. 2007, 18, 1194.

95. Machado, W.; Villar, L. S.; Monteiro, F. F.; Viana, L. C. A.; Santelli, R .E.; J. Soil. Sediment. 2010, 10, 1606.

96. Mariani, C. F.; Pompeo, M.L.M.; J. Soil. Sediment. 2008, 8, 284.

97. Paixão, J. F.; Oliveira, O. M. C.; Dominguez, J. M. L.; Coelho, A. C. D.; Garcia, K. S.; Carvalho, G. C.; Magalhães, W. F.; Mar. Pollut. Bull. 2010, 60, 474.

98. Schnitzler, D. C.; Grassi, M. T.; Quinaia, S. P.; Quim. Nova 2009, 32, 1315.

99. Martínez-Sánchez, M. J.; Navarro, M. C.; Pérez-Sirvent, C.; Marimón, J.; Vidal, J.; García-Lorenzo, M. L.; Bech, J.; J. Geochem. Explor. 2008 96, 171.

100. Ogendi, G. M.; Brumbaugh, W. G.; Hannigan, R .E.; Farris, J. L.; Environ. Toxicol. Chem. 2007, 26, 325.

101. Prica, M.; Dalmacija, B.; Roncevic, S.; Krcmar, D.; Becelic, M.; Sci. Total Environ. 2008, 389, 235.

102. Jardim, W. F.; Sodré, F. F.; Quim. Nova 2009, 32, 1083.

103. De Lange, H. J.; van Griethuysen, C.; Koelmans, A. A.; Environ. Pollut. 2008, 151, 243

104. Ankley, G. T.; Environ. Toxicol. Chem. 1996, 15, 2138.

105. Silvério, P. F.; Tese de Doutorado, Universidade de São Paulo, Brasil, 2003.

106. Buchman, M. F.; NOAA Screening Quick Reference Tables, NOAA OR\&R Report 08-1, Office of Response and Restoration Division, National Oceanic and Atmospheric Administration: Seattle WA, 2008.

107. CONAMA - Conselho Nacional do Meio Ambiente; Resolução $n^{\circ} 344$, de 25/3/2004, Diário Oficial da União, Brasília - DF, 2004.

108. CONAMA - Conselho Nacional do Meio Ambiente; Resolução $n^{\circ} 357$, de 17/3/2005, Diário Oficial da União, Brasília - DF, 2005. 